\title{
논문 3
}

\section{HeMOSU-1호 관측풍속의 불확실성을 고려한 서남해안의 풍력 발전량 예측}

이기남*, 김동현**, 권오순

\section{Prediction of Wind Power Generation at Southwest Coast of Korea Considering Uncertainty of HeMOSU-1 Wind Speed Data}

Geenam Lee*, Donghyawn Kim** and Osoon Kwon

Abstract Wind power generation of $5 \mathrm{MW}$ wind turbine was predicted by using wind measurement data from HeMOSU-1 which is at south west coast of Korea. Time histories of turbulent wind was generated from 10-min mean wind speed and then they were used as input to Bladed to estimated electric power. Those estimated powers are used in both polynominal regression and neural network training. They were compared with each other for daily production and yearly production. Effect of mean wind speed and turbulence intensity were quantitatively analyzed and discussed. This technique further can be used to assess lifetime power of wind turbine.

Key words

Offshore wind turbine(해상풍력발전기), Estimated power(예측전력), Estimation techniques(예측기법), Measure-correlatepredict(측정-상관관계-예측), Annual energy production(연간발전량), Probability distribution(확률분포)

(접수일 2014. 2. 19, 수정일 2014. 5. 15, 게재확정일 2014. 6. 11)

* 군산대학교 해양산업공학과 (Dept. of Ocean Science and Engineering, Kunsan National University)

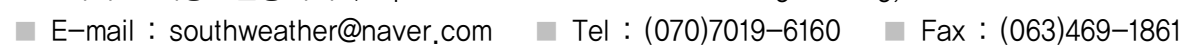

** 군산대학교 해양공학과 (Dept. of Ocean Engineering, Kunsan National University)

E-mail : welcomed@naver.com $\square$ Tel : (063)469-1862 $\square$ Fax : (063)463-9493

\section{1. 서 론}

풍력발전은 영구적인 무공해 바람에너지를 이용하는 발전 방식으로 그 용량과 크기가 점차 대형화되며 빠른 성장을 보 이고 있다. 지금까지 풍력터빈은 높은 풍속조건의 바람이 작 용하는 육상 지역에 설치되어 왔다. 그러나 육상은 지역적 한 계에 도달하였으며, 육지보다는 해상에서 바람의 조건이 더
좋고 산림 훼손 등의 단점이 발생하지 않는다. 이러한 이유로 해상풍력의 개발이 점차 증가되고 있으며, 특히 한국의 서남 해안은 대규모 해상풍력발전단지의 입지로 유망하다. 이러한 발전단지를 선정하고 건설을 시행하기에 앞서 대상 입지의 기상자료를 관측하고, 이를 이용한 생산전력의 선행적 평가 가 이루어져야 한다. 따라서 사용되는 기상자료의 정확도는 풍력발전단지 입지 선정에 매우 중요하고, 정확한 기상자료 


\section{논문 3}

의 관측은 대상 발전단지에 관측타워를 설치하여 관측하는 것이 가장 적절하다.

전력생산에 영향을 주는 요인은 해상의 공기밀도, 난류강 도 등 여러 요인이 존재하며, 생산전력은 이러한 요인으로 인 해 변화될 수 있으므로 전력 예측 및 평가에는 가급적 모든 요인이 고려되어야 한다. 이러한 요인 중 풍속이 전력 생산에 가장 지배적인 영향을 미치며, 발전기의 운영 기간에 대한 전 력 평가를 수행하기 위해서는 장기간 관측된 풍속자료를 사 용하는 것이 타당하다. 그러나 현장에서의 장기 관측은 많은 어려움이 있으므로 현장의 단기 관측 자료와 현장 인근에서 장기간 관측한 기상자료와의 상관성을 분석함으로써 현장의 장기 풍속을 추정하는 방법을 사용하는 것이 합리적이다.

본 연구에서는 기상타워인 HeMOSU-1(Herald of Meteorological and Oceanographic Sepcial Unit-1)의 단기간 관측 자료를 이용하여 $5 \mathrm{MW}$ 급 해상풍력발전기의 생산전력 예측을 위해 이론식, 회귀분석, 인공신경망을 이용하였다. ${ }^{(1)}$ 각 예측 방법에 대한 정밀도를 비교 분석하였으며, 비교적 가장 정확 한 방법을 선정하여 연간 발전량을 예측하였다. 그리고 현장 의 장기 풍속추정을 위해 $\mathrm{MCP}$ (Measure-Correlate-Predict) 방법을 사용하여 현장과 인근 관측소의 관측 자료에 대한 상 관관계를 추정하였다. ${ }^{(2)}$ 몬테카를로 시뮬레이션 방법과 실제 인근 관측소의 장기간 관측 자료를 이용하여 연간발전량을 추정하였다. 최종적으로 확률분포를 이용한 방법과 기존 결 정론적 방법의 추정된 연간발전량을 비교하였다. ${ }^{(3)}$

\section{2. 단기 발전량 예측}

본 논문에서는 장기 발전량을 예측하기에 앞서 특정 풍속 에 대한 평균출력 및 변동계수를 얻을 수 있도록 예측 모델 선정을 수행하였다. 풍속 및 터빈의 제원 등을 이용하여 출력 을 결정하는 이론적 모델과 참조값을 이용하는 회귀 및 신경 망 모델에 대한 검증을 통해 가장 적합한 모델을 선정하였다. 선정된 모델로부터 출력곡선과 변동계수곡선을 얻기까지의 과정을 Fig. 1에 흐름도로 나타내었다.

\section{1 이론적 모델}

식 (1)과 같이 출력계수, 공기밀도, Blade의 회전면적, 풍

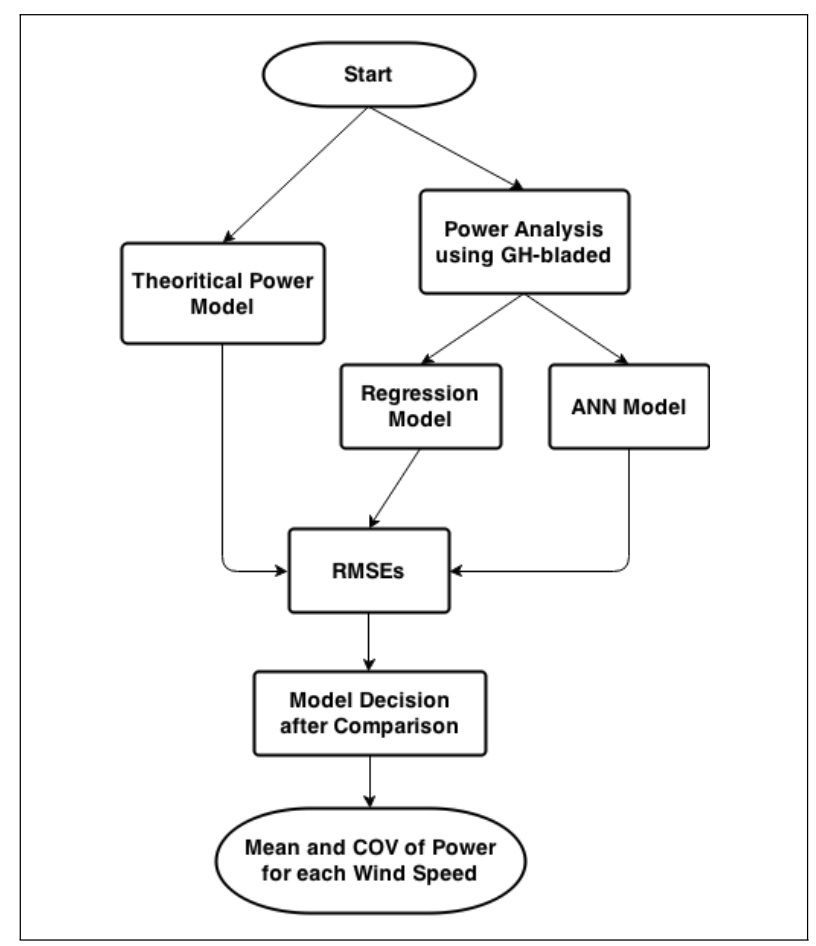

Fig. 1 Flowchart for short term wind power estimation

속을 이용하여 전력을 산정할 수 있다. 여기서 Blade의 회전 면적과 풍속이 생산 전력에 큰 영향을 미치며, 출력을 높이기 위해서는 높은 풍속이 발생하는 지역에 풍력발전기를 설치하 고, Rotor 직경을 증가하는 것이 가장 적합하다.

$$
P=C_{P} \rho \pi R^{2} V_{h}^{3}
$$

Power coefficient $\left(C_{P}\right)$ 의 경우 식 (2)를 이용하여 계산할 수 있으며, 여기서 tip speed ratio( $\lambda$ )는 식 (3)과 같이 rotor $\operatorname{speed}\left(\omega_{r}\right)$ 와 회전반경 $(R)$, 그리고 풍속 $\left(V_{h}\right)$ 을 이용하여 구 할 수 있다. ${ }^{(4)}$

$$
\begin{aligned}
C_{P}= & (0.44-0.0167 \beta) \sin [\pi(\lambda-3) \\
& \quad /(15-0.3 \beta)]-0.00184(\lambda-3) \beta \\
\lambda= & \omega_{r} R / V_{h}
\end{aligned}
$$

공기밀도는 온도 $(T)$, 습도 $(\phi)$, 대기압 $(B)$ 을 이용하여 식 (4)와 같이 산정할 수 있으며, 여기서 $R_{0}$ 와 $R_{W}$ 는 각각 공기 의 기체상수와 수증기의 기체상수로 $287.05[\mathrm{~J} / \mathrm{kgK}]$ 와 461.5 
$[\mathrm{J} / \mathrm{kgK}]$ 를 갖는다. ${ }^{(5)}$

$\rho=\frac{\frac{B}{R_{0}}-\phi P_{W}\left(\frac{1}{R_{0}}-\frac{1}{R_{W}}\right)}{T}$

$P_{W}=0.0000205 \exp (T)$

(5)

위의 식 (2)-(5)에서 구한 밀도와 출력계수를 식 (1)에 대 입하여 전력을 계산한다.

$$
E_{\text {theory }}=\sum_{\tau=1}^{P}\left(P_{\text {Bladed }}-P_{\text {theory }}\right)_{\tau}^{2}
$$

\section{2 회귀 모델}

전력은 다음의 다항식을 이용하여 추정할 수 있다.

$$
\begin{aligned}
P_{\text {poly }}= & C_{0}+\sum_{i} C_{i} X_{i}+\sum_{i j} C_{i j} X_{i} X_{j} \\
& +\sum_{i j k} C_{i j k} X_{i} X_{j} X_{k}
\end{aligned}
$$

여기서 $X_{i}$ 는 공기밀도, 평균풍속, 난류강도를 의미하며, $C_{i}, C_{i j}, C_{i j k}$ 는 최소자승법에 의해 결정될 수 있는 계수이 다. 다음과 같이 다항식에 대한 오차의 제곱을 정의할 수 있다.

$$
E_{\text {poly }}=\sum_{\tau=1}^{P}\left(P_{\text {Bladed }}-P_{\text {poly }}\right)_{\tau}^{2}
$$

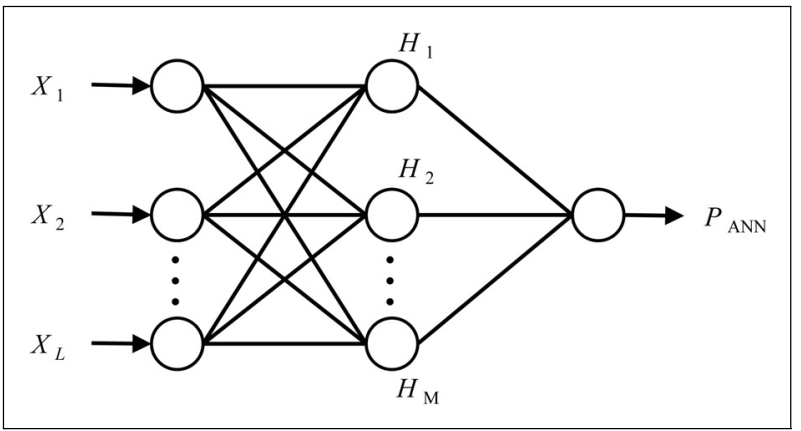

Fig. 2 A typical layout of neural network

\section{3 인공 신경망 모델}

Fig. 2는 세 개의 층으로 구성된 일반적인 신경망이다. 신경 망에 대한 입력 값 $X_{i}$ 는 풍속, 공기밀도 등과 같은 관측된 변수 를 사용 할 수 있으며, 은닉층의 출력은 다음과 같이 표현한다.

$$
\begin{aligned}
& H_{j}=f\left(\text { net }_{j}\right) \quad(j=1,2, \ldots, M) \\
& \text { net }_{j}=\sum_{i=1}^{L} W_{j i} X_{i}+b_{j}
\end{aligned}
$$

여기서 $f(\cdot)$ 는 활성함수이며, $W_{i j}$ 와 $b_{j}$ 는 각각 가중치와 bias이다. 마찬가지로 출력은 다음과 같다.

$$
P_{A N N}=f(n e t)
$$

$$
n e t=\sum_{j=1}^{M} W_{j} H_{j}+b
$$

다음과 같이 목표 값과 출력 값의 오차를 최소화하는 가중 치와 bias의 학습이 이루어져야 한다.

$$
E_{A N N}=\sum_{\tau=1}^{P}\left(P_{\text {Bladed }}^{\tau}-P_{A N N}^{\tau}\right)^{2}
$$

\section{4 수치 해석}

\subsection{1 기상 조건}

$\mathrm{HeMOSU}-1$ 은 대형 풍력 발전 단지가 계획되어 전남 안마 도 해역에 설치되어 있다. 관측 기간은 2011년 3월 1일부터 2012년 12월 31일까지 약 2년이다. 관측 자료는 풍향, 풍속, 온도, 습도, 기압이 있으며, 이 중 풍속계의 경우 Fig. 3(a)와 같이 평균 해수위로부터 $26.31 \mathrm{~m}-97.35 \mathrm{~m}$ 의 높이에 총 8 개가 설치되어 관측하였다. Fig. 4는 현장 자료의 풍속에 따른 난류 강도의 분포를 나타내며, 넓은 범위의 난류강도를 볼 수 있다.

풍속의 수직변화는 식 (12)와 같은 멱법칙을 따르며, 현장 의 관측 자료를 이용하여 추정한 풍속전단지수 $\alpha$ 는 0.0945 이다. 추정된 $\alpha$ 를 사용하여 측정된 풍속에 대해 고도보정을 수행하였다. 


$$
\frac{V_{h}}{V_{m}}=\left(\frac{H_{h}}{H_{m}}\right)^{\alpha}
$$

풍력 터빈에서 생산되는 전력은 풍속에 지배적이지만 풍속 외에도 공기밀도, 습도와 같은 여러 기상 조건 또한 전력에 영향을 미친다. 고정우 등(2012)은 전력곡선이 공기밀도의 변화에 의해 영향을 받는 것을 보여주었으며, 낮은 공기밀도 가 작용할 경우 생성되는 전력이 감소하는 것으로 나타났 다. ${ }^{(9)}$ 현승건 등(2012)은 난류강도의 변화에 따른 출력에 대 한 연구를 수행하였다. 수행 결과 낮은 풍속에서 저 난류특성 의 출력곡선이 낮은 출력을 보이고 높은 풍속에서 비교적 높 고 안정적인 출력을 보인다. 또한 고 난류 특성의 출력곡선은 낮은 풍속 구간에서 보다 높은 출력을 보이나 높은 풍속으로 갈수록 비교적 출력이 낮게 나타났다. 이는 동일한 풍속 조건 에서 고 난류강도 특성의 바람이 더 많은 풍력에너지를 갖고, 정격 풍속 이상의 풍속에서는 제어기능이 비교적 일찍 작동
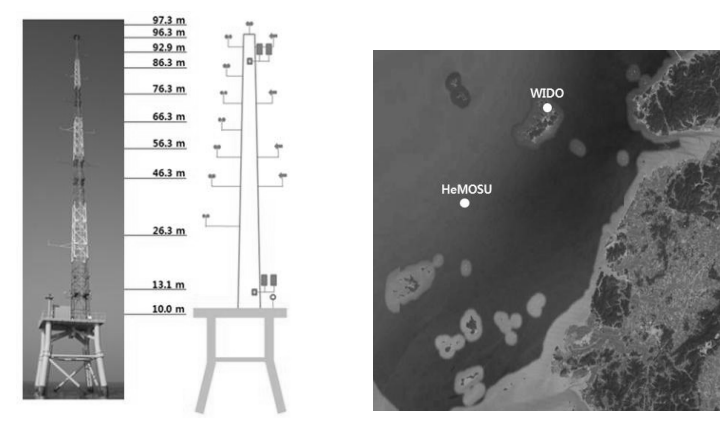

(a) wind measurement height (b) wind measurement sites

Fig. 3 Wind measurement at HeMOSU

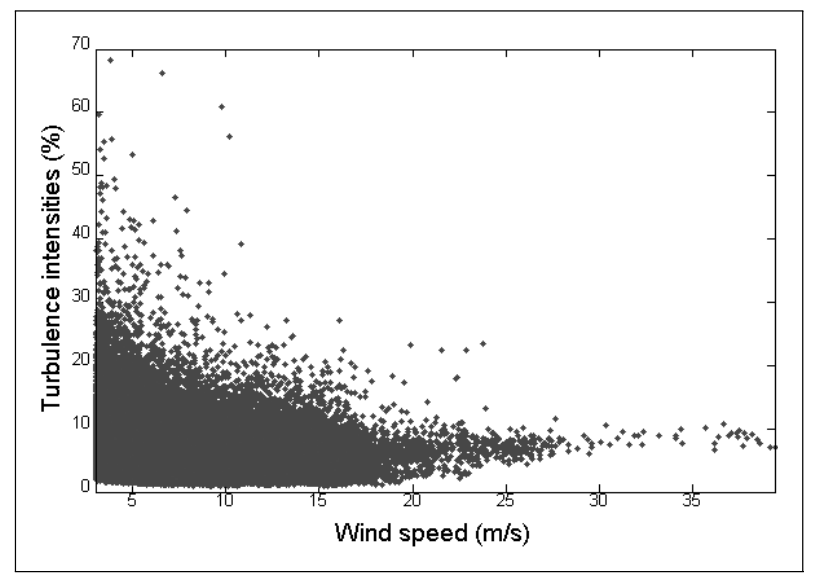

Fig. 4 Turbulence intensities and the wind speed at HeMOSU
하여 출력을 제어하기 때문이다. ${ }^{(10)}$ 이렇듯 여러 요인들을 고 려해야만 실제 전력과 근사한 결과를 얻을 수 있다.

\subsection{2 풍력터빈}

전력 예측에 사용된 해상풍력터빈은 Fig. 5 와 같은 NREL (National Renewable Energy Laboratory) 5MW급 풍력터

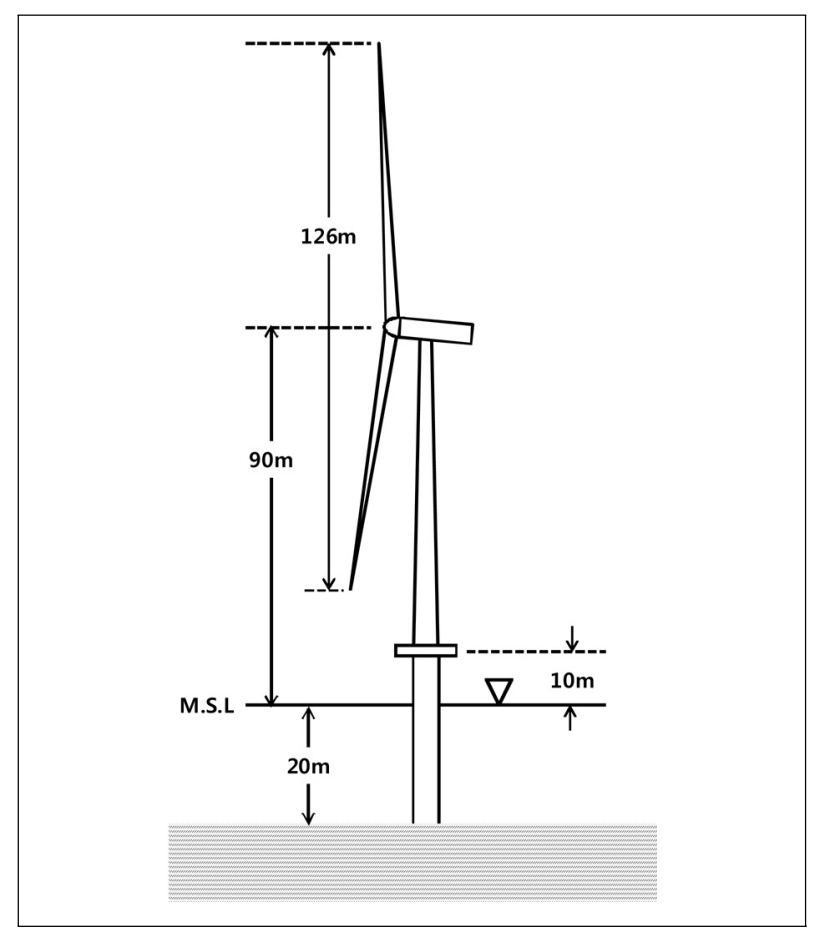

Fig. 5 NREL 5 MW offshore wind turbine

Table 1. General specification of NREL 5 MW turbine

\begin{tabular}{c|c}
\hline \multicolumn{2}{c}{ Specification } \\
\hline Rating & $5 \mathrm{MW}$ \\
\hline Rotor Orientation, Configuration & Upwind, 3 Blades \\
\hline Control & Variable Speed, Collective Pitch \\
\hline Drivetrain & High Speed, Multiple-Stage \\
Gearbox
\end{tabular}


빈을 사용하였다. ${ }^{\left({ }^{8}\right)}$ 터빈의 일반 사양은 Table 1 에 나열되어 있으며, 시뮬레이션에 사용되는 수심은 $20 \mathrm{~m}$ 로 가정하였다.

\subsection{3 전력 해석}

모든 자료에 대해 전력 해석 프로그램을 이용하여 예측 하 는 것이 적합하겠으나 다량의 자료를 해석하는데 있어 많은 시간이 소요되므로 예측 모델을 이용하여 추정할 수 있다. 앞 서 언급한 예측 모델 중 회귀 모델과 인공신경망 모델의 경우 입력 자료를 이용한 예측이 수행된다. 따라서 Table 2 와 같 이 각 항목의 범위에 대해 등분하고, 전력해석을 수행하였다. 해석에는 GL Garrad Hassan 사의 풍력 터빈 설계 및 특성 해석 프로그램인 Gh-bladed(v4.4)를 사용하였다.

\section{5 발전량 예측}

현장의 매 10 분 평균풍속과 이를 $\mathrm{Gh}$-bladed에 입력하여 계산된 $\omega_{r}$ 를 식 (3)에 대입하고, 식 (2)를 이용하여 $C_{P}$ 를 계 산하였다. 계산된 값과 관측 풍속을 식 (1)에 입력하여 이론 적 모델을 이용한 생산 전력을 예측하였다.

다항식 회귀분석을 식 (7)을 이용하여 수행하였다. Table 2 의 조건인 평균풍속, 공기밀도, 난류강도와 수치해석 결과 를 사용함으로써 식 (7)에서의 회귀분석계수를 산정하였다. 이러한 회귀모델을 이용하여 생산 전력을 예측하였다.

인공신경망은 Fig. 6 과 같이 3 개의 층으로 구성되어있고, 입력값은 회귀 모델의 입력값과 같다. 5000 의 epochs와 SSE

Table 2. Range of data for power analysis

\begin{tabular}{c|c|c}
\hline Item & Range & Divide number \\
\hline Mean wind speed & $3.00 \sim 40.00(\mathrm{~m} / \mathrm{s})$ & 20 \\
\hline Turbulence intensities & $0.60 \sim 68.19(\%)$ & 10 \\
\hline Air density & $1.10 \sim 1.355\left(\mathrm{~kg} / \mathrm{m}^{3}\right)$ & 5 \\
\hline
\end{tabular}

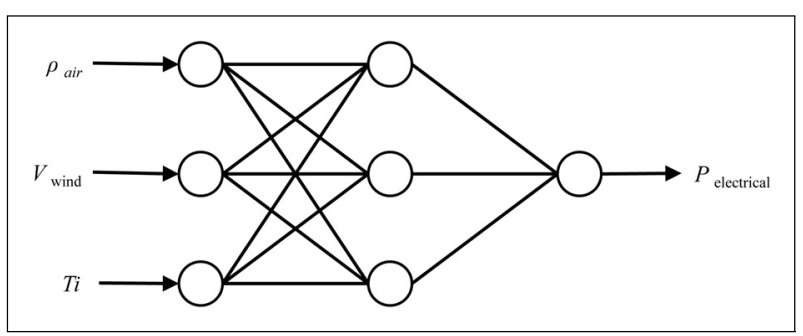

Fig. 6 ANN for Power prediction (sum squared error)가 $10^{-5}$ 이하를 만족하도록 학습조건을 지정하였으며, 학습이 수행된 신경망 모델을 이용하여 생산 전력을 예측하였다.

\subsection{1 모델 검증}

상기 모델들을 이용하여 예측된 출력곡선을 Fig. 7에 나타 내었으며, Table 3은 각 모델에 대한 RMSEs(Root mean square errors)이다. 그 결과 전력 추정 모델 중 오차가 비교적 적은 인공신경망이 적합함을 볼 수 있다. 또한 이론적 모델은 기상

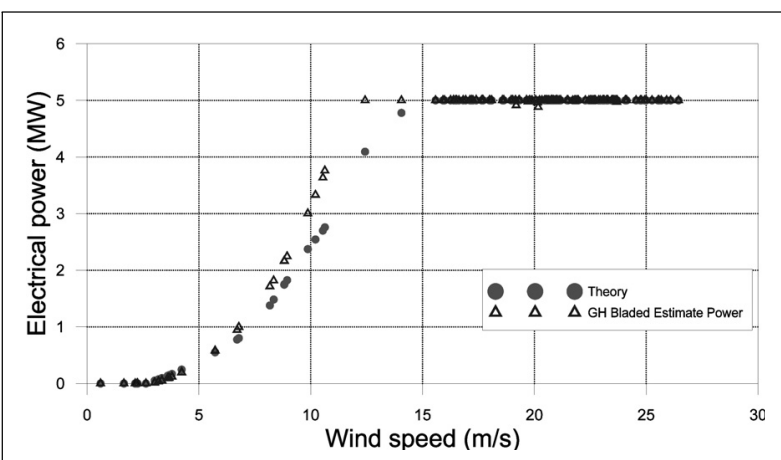

(a) Theory

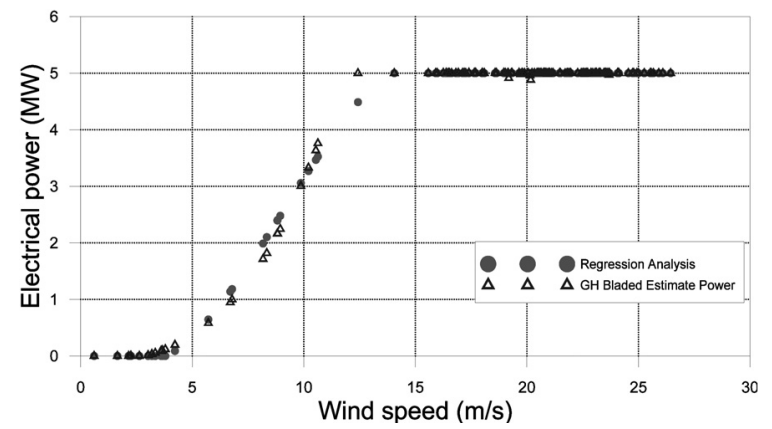

(b) Regression analysis

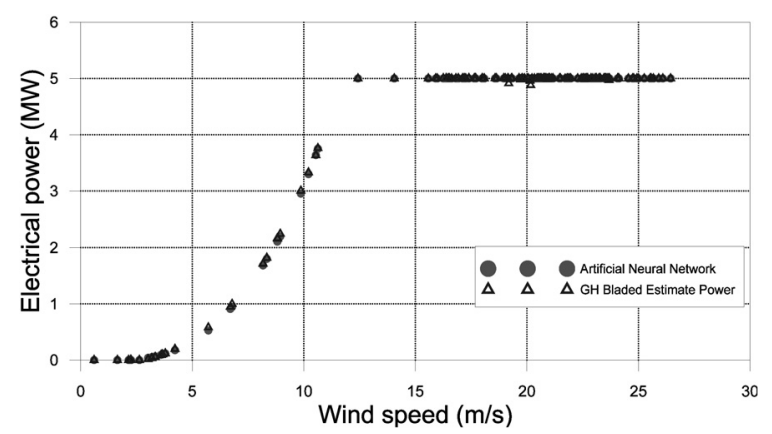

(c) Artificial Neural Network

Fig. 7 Power curve of prediction method and true value 
Table 3. RMSEs of power estimation

\begin{tabular}{c|c|c|c}
\hline & Theory & Regression analysis & Artificial neural network \\
\hline RMSE & 2.593 & 0.076 & 0.018 \\
\hline
\end{tabular}

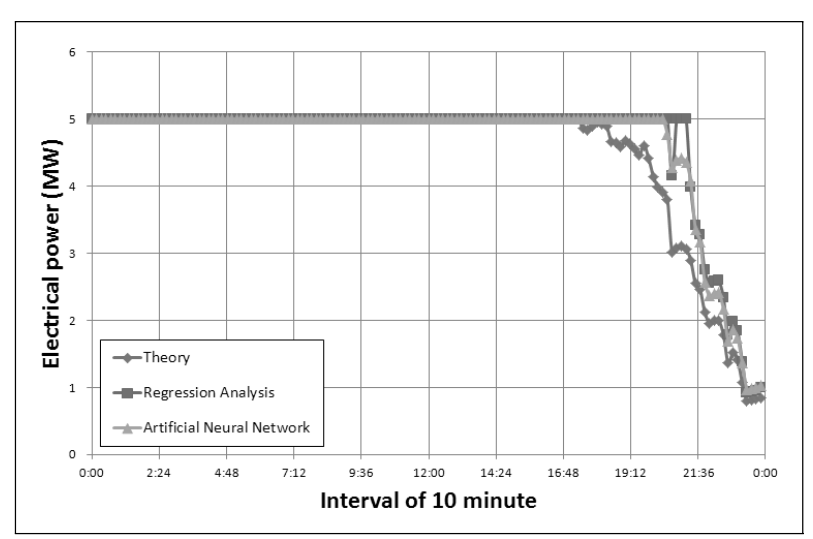

Fig. 8 Power curve for interval of 10 minute by prediction method

조건을 모두 고려하지 않아 큰 오차를 보였다. Fig. 8은 풍속 이 급격히 감소한 2011년 4월 30 일 관측 자료에 대한 전력 추정 결과이다. 이는 큰 변동성을 가진 풍속이 작용할 때 추 정 오차가 커진다고 할 수 있다.

\subsection{2 연간 발전량 예측}

현장의 약 2 년간 관측풍속을 이용하여 생산된 발전량을 Table 4 와 같이 각 모델에 대해 비교하여 나타냈다. 인공신 경망에 의한 연간 발전량을 기준으로 이론적 모델이 $14 \%$ 감소된 결과를 보였으며, 다항식 회귀모델은 $1 \%$ 오차를 보 였다.

\section{3. 장기 발전량 예측}

\section{1 예측방법}

장기간 발전량은 풍속의 확률분포를 이용하여 구할 수 있 다. 그러나 HeMOSU에서 관측한 자료는 약 2년이고, 해당 기간의 풍속으로부터 얻은 분포가 터빈의 수명 내에 발생하 는 풍속을 대변할 수 있는지 확실하지 않다. 따라서 현장의 장기간 풍속 자료를 이용한 확률분포가 필요하며, 이는 일정 수준 이상의 상관성이 있는 인근 관측소의 장기간 관측 자료
Table 4. RMSEs of power estimation

\begin{tabular}{c|c|c|c}
\hline & Theory & Regression analysis & Artificial neural network \\
\hline \multirow{2}{*}{2011} & 8.14 & 9.63 & 9.50 \\
& $(0.86)$ & $(1.01)$ & $(1.00)$ \\
\hline \multirow{2}{*}{2012} & 11.12 & 12.97 & 12.89 \\
& $(0.86)$ & $(1.01)$ & $(1.00)$ \\
\hline
\end{tabular}

를 이용하여 추정할 수 있다. 이렇듯 각 지점 자료의 상관성 을 이용하여 장기간 자료를 추정하는 방법을 $\mathrm{MCP}$ 기법이라 한다. 현장 인근의 기상대로부터 얻은 장기 관측 풍속을 이용 하여 현장의 풍속이 추정되고, 이로부터 현장의 장기 전력을 추정할 수 있다. 현장과 인근 기상대의 바람 자료에 대한 선 형 상관관계를 이용하여 장기 바람을 추정할 수 있다. ${ }^{2(, 6)}$ Rogers 등(2005)은 분산비를 이용하여 추정할 수 있는 방법 으로 다음과 같은 선형 방정식을 제안하였다. ${ }^{(7)}$

$$
\begin{aligned}
& V=a U+b \\
& a=\frac{\sigma_{V_{S}}}{\sigma_{U_{S}}} \\
& b=V_{S, a v g}-a U_{S, a v g}
\end{aligned}
$$

여기서 $U$ 와 $V$ 는 인근 기상대와 현장에서의 풍속이며, $\sigma_{i}$ 는 $i$ 의 표준편차이다. 또한 아래첨자인 $S$ 와 $a \mathrm{av}$ 는 각각 단기 자료와 평균을 의미한다. 두 풍속의 상관 계수는 다음과 같은 방정식을 사용하여 계산할 수 있다.

$$
R_{U_{S} V_{S}}=\frac{\sum U_{S} V_{S}-n U_{S, a v g} V_{S, a v g}}{(n-1) \sigma_{U_{S}} \sigma_{V_{S}}}
$$

여기서 $n$ 은 샘플 풍속의 수이다.

현장의 장기 풍속 추정에는 현장으로부터 약 $22 \mathrm{~km}$ 떨어진 위도의 자료를 사용하였다. 위도의 자료는 1997년부터 2012 년까지 16년 동안 관측되었다. 식 (16)으로부터 산정한 상관 계수는 0.7 로 상당한 연관성이 있으므로 $\mathrm{MCP}$ 기법을 적용하 여 상관계수 $a$ 와 $b$ 를 산정할 수 있다. 그러나 이러한 상관계 수는 Fig. 9 와 같이 일정한 선형 방정식의 계수로써 분산성을 갖지 못한다. 따라서 위 계수들이 분산성을 가질 수 있도록 
새로운 확률변수 $\gamma$ 를 적용하였다.

두 확률변수인 인근 관측소의 풍속과 $\gamma$ 는 몬테카를로 시뮬 레이션을 이용하여 생성할 수 있으며, 이를 위해 각 확률변수

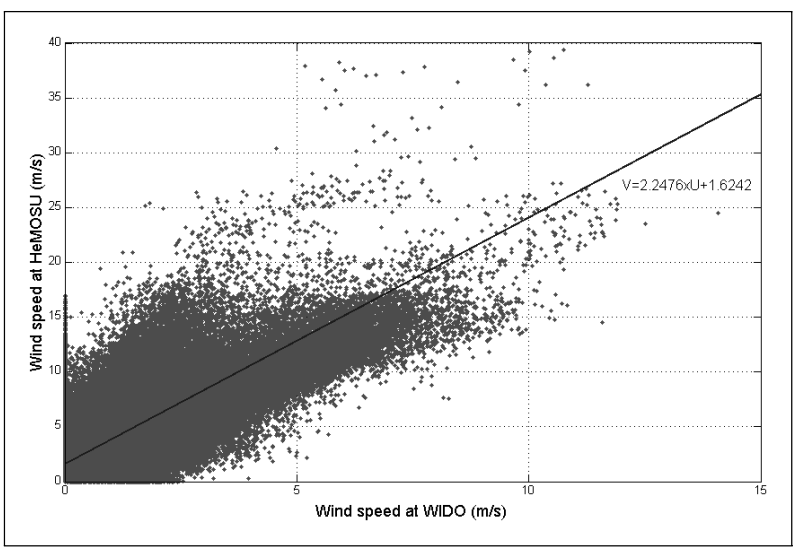

Fig. 9 Distribution of wind speed WI-DO and HeMOSU

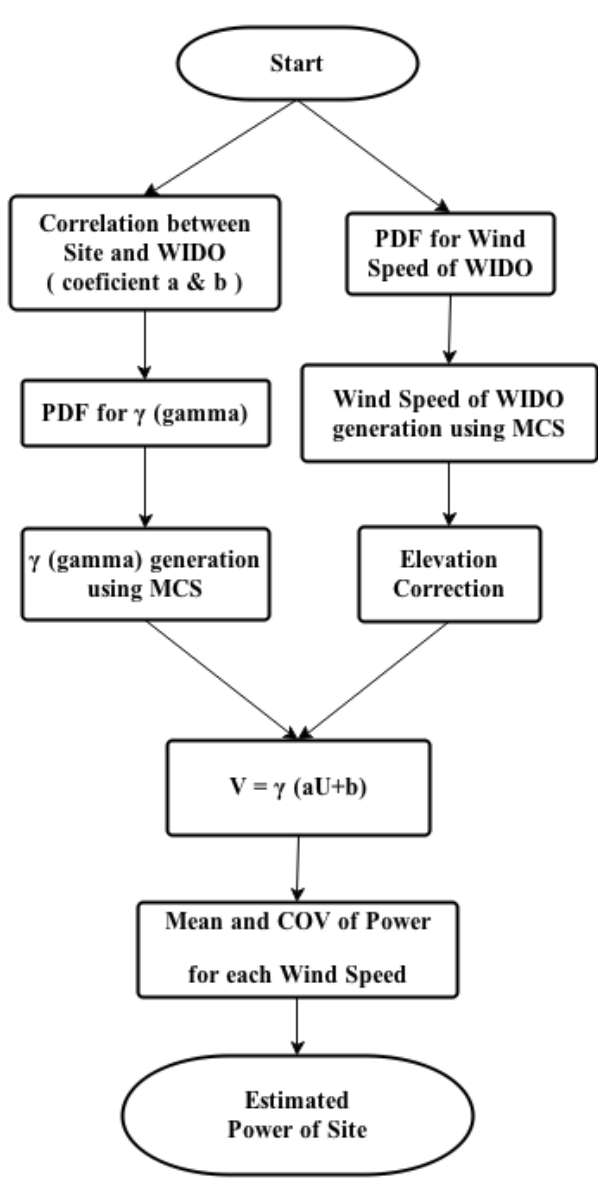

Fig. 10 Flowchart for long term wind power estimation
의 확률분포를 사용한다. 생성한 값을 관계식에 대입하여 현 장의 풍속을 추정할 수 있으며, 추정된 풍속은 고도보정을 수 행하여 단기 발전량 예측에서 얻은 출력곡선과 변동계수곡선 으로부터 해당 풍속에 대한 전력의 평균과 변동계수를 구할 수 있다. 각 확률변수들의 확률분포를 이용하여 현장의 전력 예측까지의 과정을 흐름도로 나타내면 Fig. 10과 같다.

\section{2 풍속의 확률분포}

현장과 위도의 풍속분포는 모두 식 (17)의 Weibull 분포를 사용하여 추정하였다.

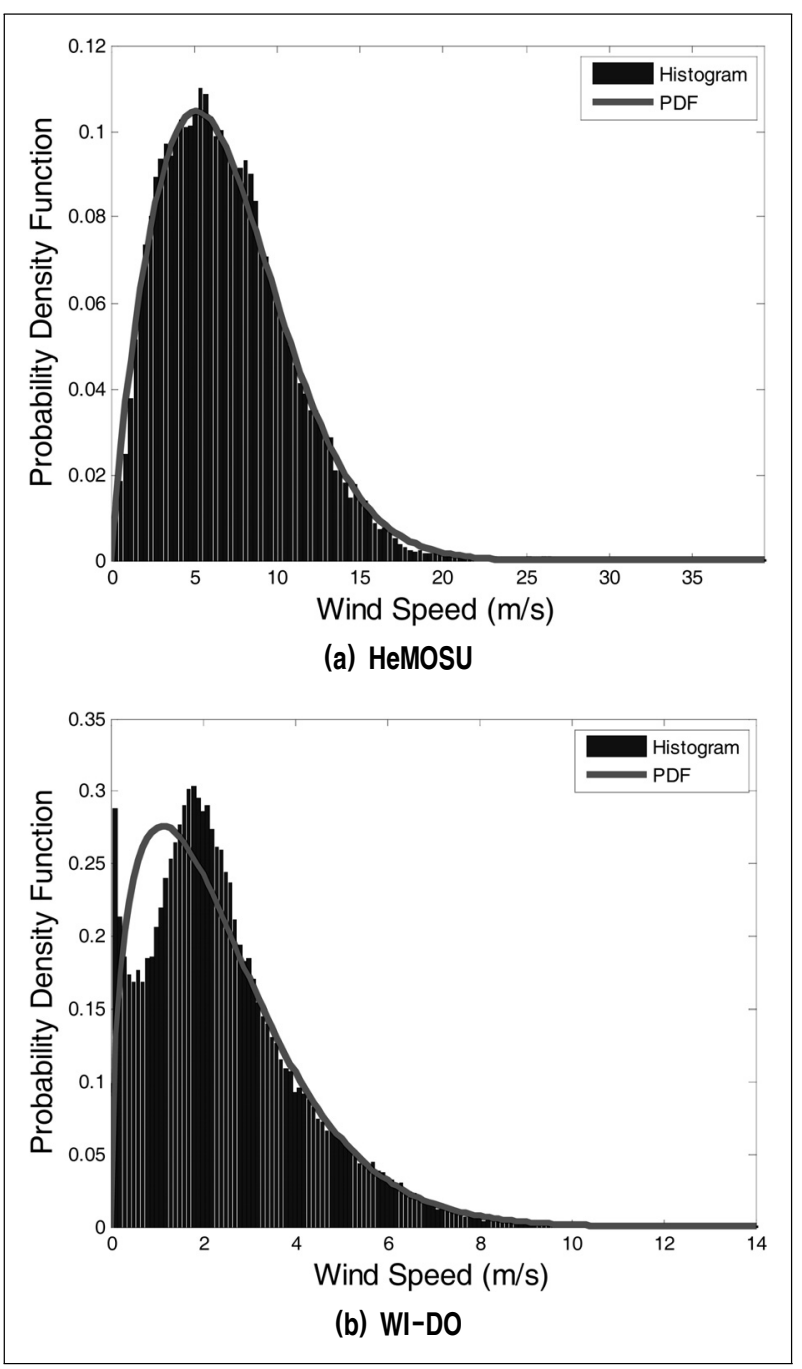

Fig. 11 PDFs of wind speed 


\section{논문 3}

$$
f_{X}(x)=\frac{k}{c}\left(\frac{x}{c}\right)^{k-1} \exp \left\{-\left(\frac{x}{c}\right)^{k}\right\}
$$

여기서 $c$ 와 $k$ 는 각각 scale parameter와 shape parameter 이다. Fig. 11에서 볼 수 있듯이 확률밀도함수는 현장과 위도 에서 2 년간의 10 분 평균풍속을 이용하여 추정하였다. 위도 자료 중 낮은 풍속에서는 일치하지 않는 부분이 있으나 대부 분 풍속 범위에서 측정 데이터와 잘 일치하였다.

\section{3 전력의 확률분포}

특정 풍속에서 생산전력은 평균이 성능곡선에 근접한 임의

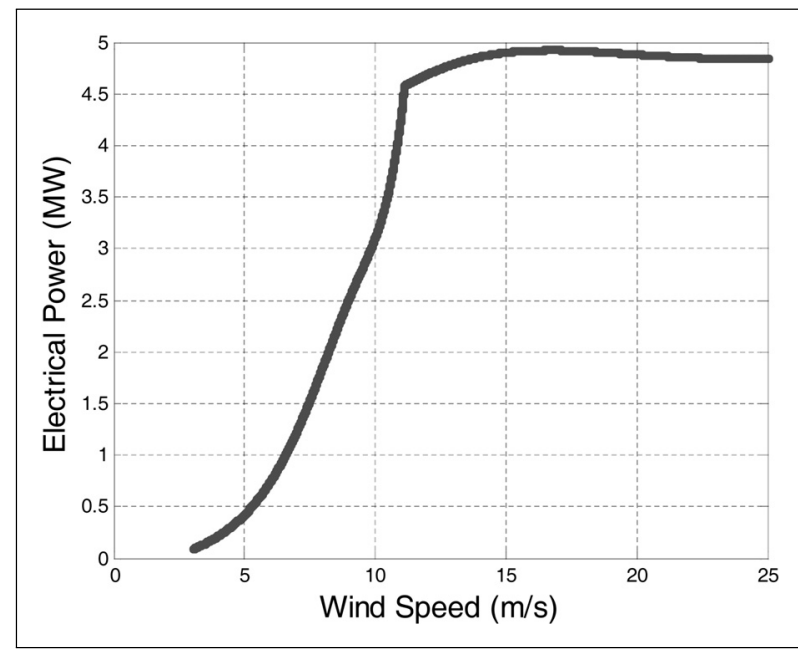

Fig. 12 Mean power curve

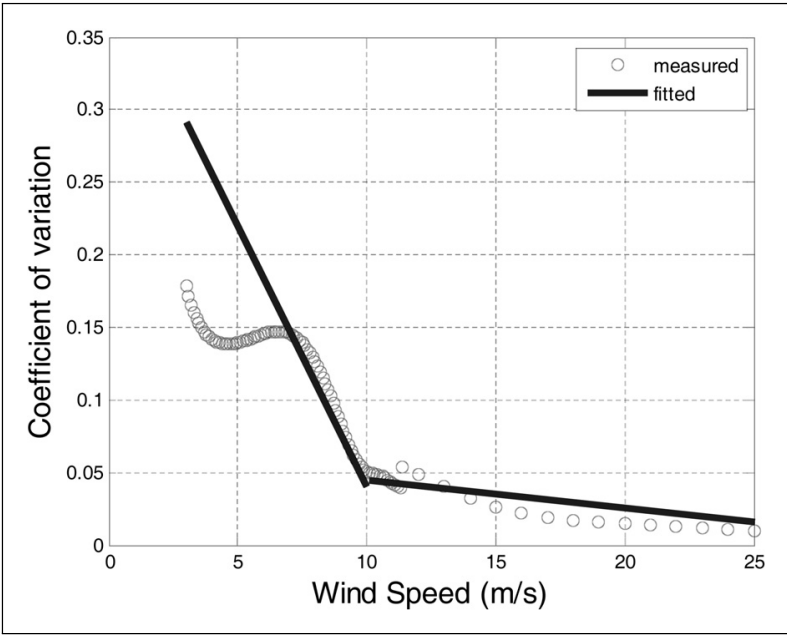

Fig. 13 Coefficient of variation
의 값이 되므로 확률적 접근이 필요하며, 이러한 출력 곡선의 변동량에 대한 확률분포를 정규분포로 가정하였다(권순덕, 2008). ${ }^{(3)}$ 특정 풍속에서 생산 전력의 평균과 표준편차는 단 기 발전량 예측에서 얻은 Fig. 12의 추정 평균 전력과 Fig. 13 의 변동계수를 이용하여 산정할 수 있다.

\section{4 연간 발전량}

연간 발전량(annual energy production, $\mathrm{AEP}$ )은 몬테카 를로 시뮬레이션을 이용하여 추정할 수 있다. 10 분 평균 풍속 을 위도의 풍속 분포를 이용하여 생성할 수 있고, $\mathrm{MCP}$ 기법

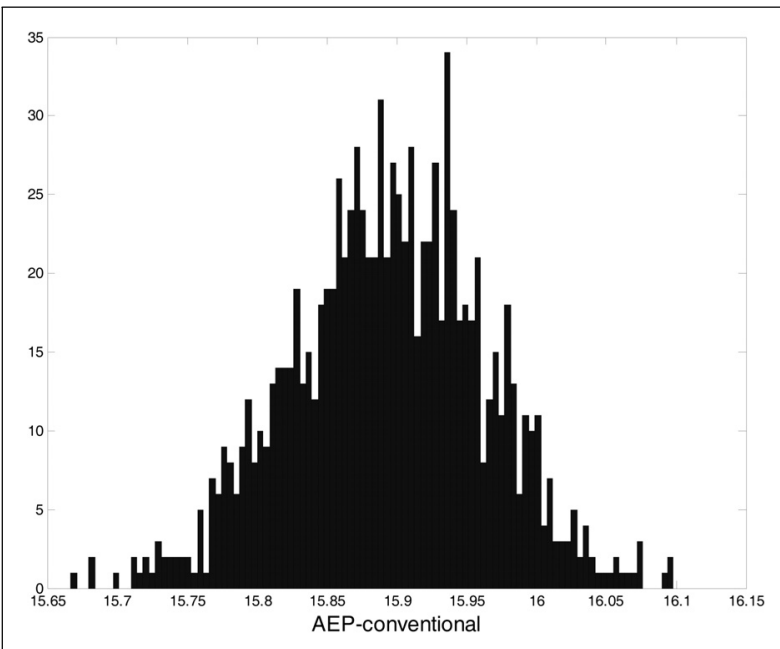

(a) AEP_conventiona

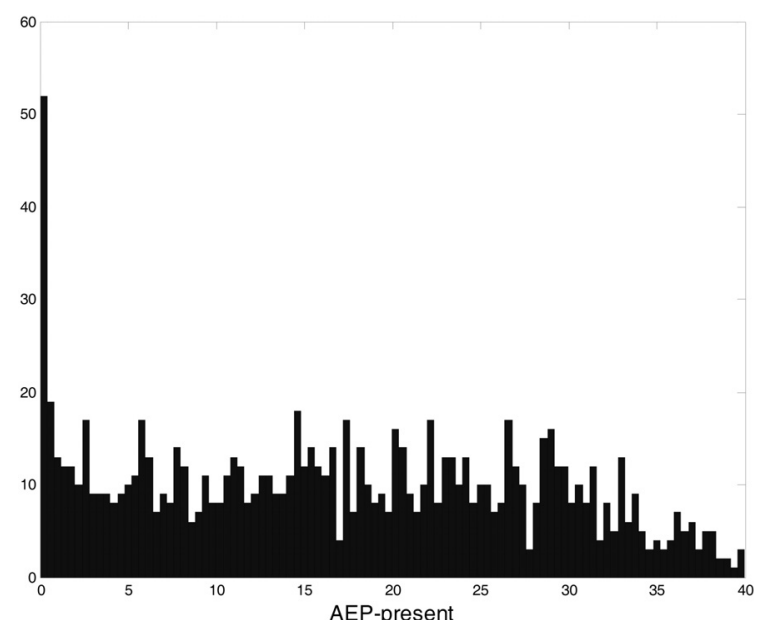

(b) AEP_present

Fig. 14 Histogram of AEP 
을 이용하여 현장의 풍속을 결정한다. 풍속전단지수의 확률 분포를 이용하여 현장 풍속에 대해 고도보정을 수행하고, 해 당 풍속에 대한 출력을 구할 수 있다. 이러한 출력을 시간당 발전량으로 환산하여 모두 합산하면 연간발전량을 산정할 수 있으며, 시뮬레이션을 여러 번 반복하면 예상 $\mathrm{AEP}$ 를 추정할 수 있다. Fig. 14는 두 가지 방법에 대한 AEP 분포를 보여주 고 있다. Fig. $14(\mathrm{a})$ 는 $\mathrm{MCP}$ 기법에서 일정한 값의 $\gamma$ 를 사용 하였으며, Fig. 14(b)는 $\gamma$ 를 임의의 변수로 간주하고, 확률분 포로부터 $\gamma$ 를 생성하여 사용하였다. 두 방법에 대한 AEP의 평균값은 각각 $19.04[\mathrm{GWh}]$ 와 20.39[GWh]이며, 평균은 서 로 근사하지만 확률분포를 고려한 방법이 평균을 기준으로 비교적 큰 편차를 갖는다.

위도의 16 년에 해당하는 풍속자료를 사용함으로써 Fig. 15 와 같은 $\mathrm{HeMOSU}$ 영역의 $\mathrm{AEP}$ 를 추정하였다. 확률분포 를 고려한 방법은 기존의 방법보다 약간 큰 $\mathrm{AEP}$ 결과를 보 였고, Table 5는 16년간의 총 생산전력을 보여주고 있다. $\mathrm{AEP}$ 추정에서 중요한 점은 $\mathrm{MCP}$ 기법과 풍속 모두 불확실성 에 따른 변화를 보여주는 것이므로 추정 시 이를 고려해야 한다.

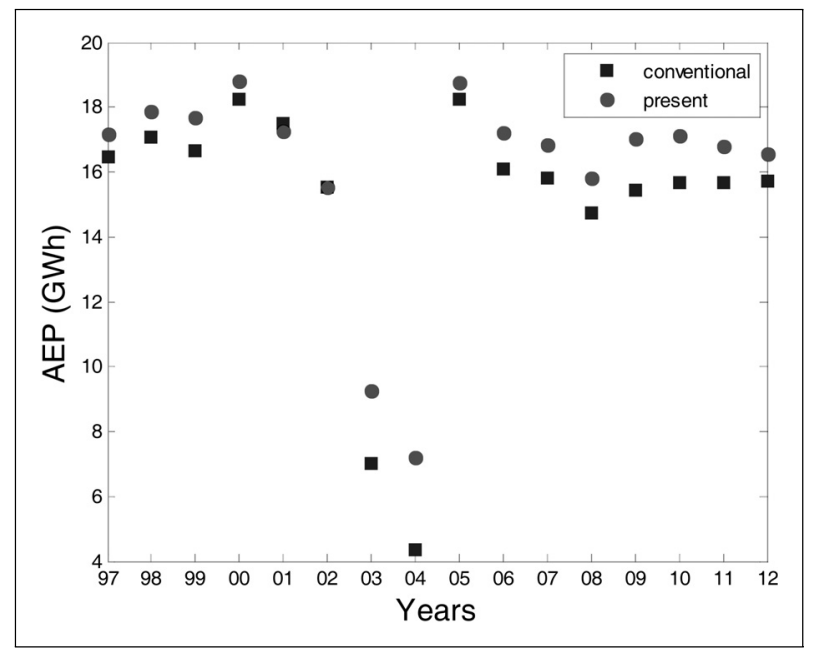

Fig. 15 AEP using measure data

Table 5. Total Energy Production (1997-2012)

\begin{tabular}{c|c|c}
\hline & Conventional & Present \\
\hline Total Energy Production [GWh] & 240.77 & 256.88 \\
\hline
\end{tabular}

\section{4. 결 론}

$\mathrm{HeMOSU}$ 에서 측정된 풍속 자료를 이용하여 $5 \mathrm{MW}$ 급 해상 풍력터빈에 대한 전력을 추정하였다. 이론적 모델과 회귀모 델, 그리고 인공신경망 모델을 $\mathrm{Gh}$-bladed에서 생성된 전력 과 비교하였다. 그 결과 인공신경망 모델이 가장 정확하였고, 난류강도가 적용되지 않은 이론적 모델이 비교적 큰 오차를 나타내었다. 장기간 $\mathrm{AEP}$ 추정을 위해 풍속의 확률분포와 $\mathrm{MCP}$ 기법을 사용하였다. 인근의 기준점과 현장에 대한 관계 의 확률적 변화가 고려되었다. $\mathrm{AEP}$ 는 기준점에서 $\mathrm{MCP}$ 기법 과 풍속의 장기간 변화를 이용하여 추정되었으며, 선형 $\mathrm{MCP}$ 기법인 기존 방법과 확률적 $\mathrm{MCP}$ 기법의 평균값은 매우 근사 하게 나타났다. 그러나 확률적 $\mathrm{MCP}$ 기법의 적용으로 인한 $\mathrm{AEP}$ 의 변동성은 매우 중요하다. 그러므로 $\mathrm{MCP}$ 의 불확실성 은 풍력발전에 대한 $\mathrm{AEP}$ 추정 시 고려되어야 한다.

\section{후 기}

본 연구는 2012년도 지식경제부의 재원으로 한국에너지기 술평가원(KETEP)의 지원을 받아 수행한 연구 과제(NO.201 24010203240)입니다.

\section{References}

[1] HeMOSU-1, 2013, Marine Meteorological Tower Acquisition Data (2011.3.1. - 2012.12.31.), Korea Electric Power Corporation.

[2] Manwell, J.F., Rogers, A.L., McGowan, J.G., Bailey, B.H., 2002, "An offshore wind resource assessment study for New England”, J. of Renewable Energy, Vol. 27, No. 2, pp. 175-187.

[3] Kwon, S.D., 2008, "Assessment of Wind Energy Potential Based on Short-term Measurement", J. of Wind Engineering Institute of Korea, Vol. 12, No. 3, pp. 165-171.

[4] Ezzeldin, S., Abdin and Wilson Xu, 2000, "Control Design and Dynamic Performance Analysis of a Wind TurbineInduction Generator Unit”, IEEE Transactions on Energy Conversion, Vol. 15, pp. 91-96. 
[5] IEC, 2005, "Wind turbine - Powre performance measurements of electricity producing wind turbines", IEC/ 61400-12-1.

[6] Kim, H.G., 2005, "Analysis of Wind shear Patterns and Application of Measure-Correlate-Predict at Pohang Region”, J. of the Korean Society for New and Renewable Energy, Vol. 1, No. 2, pp. 26-33.

[7] Rogers, A.L., Rogers, J.W., Manwell, J.F., 2005, "Comparison of the performance of four measure-correlatepredict algorithms", J. of Wind Engineering and industrial aerodynamics, Vol. 93, pp. 243-264.

\section{이 기 남}

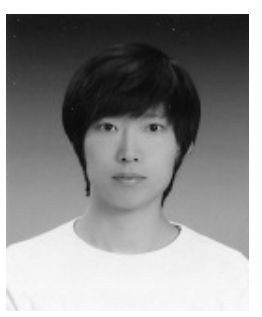

2013년 군산대학교 해양건설공학과 공학사

현재 군산대학교 해양산업공학과 석사과정

(E-mail : southweather@naver.com)

\section{권 오 순}

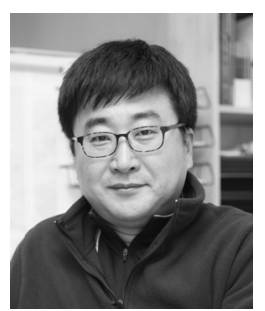

1990년 서울대학교 공과대학 토목공학과 학사 1994년 서울대학교 공과대학 토목공학과 석사 1998년 서울대학교 공과대학 토목공학과 박사

현재 한국해양과학기술원 연안 개발·에너지 연구부 책임연구원 (E-mail : oskwon@kiost.ac)
[8] Jonkman, J., Butter field, S., Musial, W., Scoot, G., 2009, "Definition of 5-MW Reference Wind Turbine for Offshore System Development”, NREL/TP-500-38060.

[9] Ko, J.W., 2012, "An Accuracy Estimation of AEP Based on Geographic Characteristics and Atmospheric Variations in Northern East Region of Jeju Island", J. of the Korean Society of Surveying, Vol. 30, No. 3, pp. 295-303.

[10] Hyun, S.G., Ju, Y.C., Kim, K.H., 2012, "A study on the effect of wind turbulence intensity on the power performance of wind turbine system", J. of the Korean Solar Energy Society, Vol. 32, No.4, pp. 17-23.

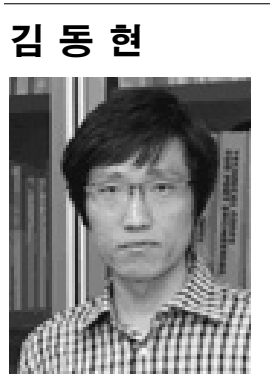

1994년 한국과학기술원 정밀공학과 공학사 1996년 한국과학기술원 토목공학과(구조공학) 공학석사

2000년 한국과학기술원 토목공학과(구조공학) 공학박사

현재 군산대학교 해양공학과 교수

(E-mail : welcomed@naver.com) 